\title{
PENTINGNYA SELF REGULATED LEARNING BAGI PESERTA DIDIK DALAM PENGGUNAAN GADGET.
}

\author{
Novidya Yulanda \\ Dosen Program Studi Pendidikan Ekonomi Universitas Indraprasta PGRI \\ Email:novidyayulanda@gmail.com
}

\begin{abstract}
Abstrak
Self Regulated Learning (SRL), merupakan sebuah konsep tentang pengelolaan diri dalam belajar. Teori kognisi social dari Bandura (1997) menjelaskan bahwa pribadi (person),perilaku(behavior),danlingkungan (environment) merupakan sebuah komponen yang tak terpisahkan. Ketigaaspek determinaninisalingberhubungan sebab- akibat,dimanapersonberusaha untuk meregulasi dirisendiri(selfregulated), hasilnyaberupakinerjaatauperilaku, dan perilakuiniberdampak padaperubahan lingkungan, dandemikianseterusnya.Artikel ini membahas tentang pentingnya selfregulated learning bagi peserta didik dalam penggunaan gadgetsebagai media yang sering digunakan anak dalam kegiatan mencari informasi di dalam proses pembelajaran. Gadget sebagai alat yang canggih mestinya dapat memberikan banyak manfaat ketimbang akibat buruk yang muncul karena kesalahan pemakaiannya.Oleh karena itu, diperlukan kreativitas bagi pemilik gadget sehingga dampak buruk dapat dihindari dan hasil positif dapat diraih.Penelitian mengatakan bahwa yang mempengaruhi tumbuhnya Self Regulated Learning adalah self efficacy dan dukungan sosial, kedua hal ini berdampak pada positif terhadap individu karena apabila individu tersebut mampu mengelola secara efektif pengalaman belajarnya sendiri sehingga mencapai hasil belajar yang optimal. Disisi lain self regulated learningdapat juga digunakan oleh sebagian guru/dosen sebagai model/strategi pembelajaran untuk meningkatkan proses pembelajaran di kelas.
\end{abstract}

Kata kunci : Self Regulated Learning, Informasi, Dampak Gadget

\section{PENDAHULUAN}

Zamanglobalisasisaat ini, mediakomunikasiberupagadget (handphone, smartphone,laptop, tablet, note, mp3dan lain-lain) merupakan barangyang hampir dimiliki oleh setiap orang mulaidariyang tuamaupunyang muda bahkananak-anakusia 7-15tahunsudahdapatmenggunakangadgetdanmengerti akan pengoprasian fasilitas gadget (internet, game, sosial media, telepon dan SMS).

Kemajuan Teknologi Informasi dan Komunikasi (TIK) ini memang memberikan banyak dampak positif,salah satunya untukmemudahkanmanusia mencari informasi dari belahan dunia manapun, dan kemudahan berkomunikasi dengan orang -orang yang tidak bias bertemu secara langsung. Tapi, dibalik itu semua adapengaruhnegatif yangtanpakita sadariakantimbuldaripenggunaangadget, terutama untuk anak yang masih dalam usia sekolah. permasalahan yang bisa kita lihat secara nyata berupa pelanggaran-pelanggaran dalam penggunaan gadget di sekolah. Peserta didik bisa dengan bebas membuka aplikasi jejaring sosial dan membuka situs-situs yang tidak 
berhubungan dengan pelajaran dan parahnya lagi itu situs yang bukan diperuntukkan bagi anak-anak. Selain itupenggunaan Gadget secara berlebihan dapat berpengaruh pada interaksi sosial anak terhadap lingkunganya baik lingkungan internal (keluarga) maupun eksternal (lingkungan sekolah dan pertemanan). Selain itu, tanpa disadari seseorang yang sering manggunakan gadget dapat menyebabkan terjadinya kesenjangan sosial dalam bermasyarakat, dan yang lebih parahnya lagi bisa berakibat kepada perkembangan psikologis peserta didik tersebut.

Pendidikan merupakan suatu usaha sadar dan terencana dalam mewujudkan proses belajar sepanjang hayat. Secara umum, tujuan belajar itu ada tiga, yaitu (1) Untuk mendapatkan pengetahuan (2) Penenaman konsep dan keterampilan (3) Pembentukan sikap. untuk itu pendidikan di sekolah merupakan salah satu cara untuk mengendalikan pemakaian gadget oleh peserta didik agar bermanfaat dan memiliki tujuan yang positif dalam proses belajar mengajar.

Self Regulated Learning (SRL) atau pengelolaan diri dalam belajar merupakan suatu cara yang dapat digunakan dan dikembangkan untuk mencapai tujuan dari pendidikan di atas dan membantu peserta didik mengendalikan pemakaian gadget secara berlebihan.Pintrich (1990: 4) mengatakan bahwa "peserta didik dapat memahami bagaimana mereka harus belajar, siswa mengetahui tentang bagaimana mereka memilih strategi dalam meregulasi dirinya dalam belajar (Self-Regulated Learning)" yang akan merefleksikan tujuan jangka panjang bagi pendidikan mereka, dan hal ini berkaitan dengan bagaimana siswa mempunyai keterampilan dalam belajar. Tugas guru menurut Usman (2006:26) sebagai pendidik, pengajar dan melatih berarti "meneruskan dan mengembangkan ilmu pengetahuan dan teknologi di sekolah dan harus mampu menarik simpati peserta didik". apabila itu terlaksana, maka pelajaran apapun yang diberikan akan memotivasi peserta didik untuk meningkatkan hasil belajar.

Berdasarkan paparan di atas, ada beberapa masalah yang akan dibahas lebih dalam, yaitu: (1) Paradigma Self Regulated Learning (SRL), (2) Self Regulated Learning (SRL) dalam mengurangi dampak penggunaan gadget. Metode yang digunakan dalam penelitian ini adalah metode kajian pustaka. 


\section{PEMBAHASAN}

\section{Paradigma Self Regulated Leaning}

Self regulated learning dalam istilah bahasa Indonesia disebut sebagai “pengelolaan diri dalam belajar” merupakan suatu strategi belajar. Pengelolaan diri dalam belajar didasari oleh asumsi triadik resiprokalitas (triadic reciprocality) dari Bandura (1997:67). Terdapat tiga aspek determinan atau faktor yang berpengaruh dalam pengelolaan diri dalam belajar, yakni “aspek diri, perilaku dan lingkungan”. Keterlibatan ketiga proses ini saling menjadi kausalitas bagi proses yang lain, dimana (a) person berusaha untuk meregulasi diri sendiri (self regulate), (b) hasilnya berupa kinerja atau perilaku, dan (c) dampaknya pada perubahan lingkungan dan demikian seterusnya, dalam proses tersebut masing-masing aspek determinan saling berpengaruh (Zimmerman \& Bandura, 1994:67).

Paris (2002:7) menyatakan bahwa "Peserta didik yang melaksanakan pengelolaan diri dalam belajar mengambil tanggungjawab terhadap kegiatan belajar mereka. Mereka mendefinisikan tujuan dan masalah-masalah yang akan dihadapi, mengembangkan standar tingkat kesempurnaan dalam pencapaian tujuan, dan mengevaluasi cara yang paling baik untuk mencapai tujuan”.

Self Regulated Learning (SRL), sebagai belajar mandiri dapat digunakan untuk mengembangkan dirinya, untuk mencapai kesuksesan, sehingga seharusnya dimiliki oleh peserta didik, mahasiswa, guru, dosen maupun pembelajar lainnya. Pengertian yang diberikan oleh para ahli, (SRL) lebih mengarah pada kehidupan pribadi setiap individu dalam memandang belajar untuk dirinya sendiri.

Zimmerman (1986: 307-312) mengemukakan bahwa dengan Self Regulated Learning peserta didik, dapat diamati sejauh mana partisipasi aktif mereka dalam mengarahkan proses-proses metakognitif, motivasi dan perilakunya di saat mereka belajar. Proses metakognitif adalah proses dimana siswa mampu mengarahkan dirinya saat belajar, mampu merencanakan, mengorganisasikan, mengarahkan diri sendiri dan melakukan evaluasi diri pada berbagai tingkatan selama proses perolehan informasi.

Berdasarkan dari beberapa pengertian di atas, dapat disimpulkan bahwa regulasi diri (self regulation) adalah kemampuan dalam mengontrol, mengatur, merencanakan, mengarahkan, dan memonitor perilaku untuk mencapai suatu tujuan tertentu dengan 
menggunakan strategi tertentu dan melibatkan unsur fisik, kognitif, motivasi, emosional, dan sosial.

\section{Self Regulated Learning (SRL) dalam mengurangi dampak penggunaan gadget}

Gadget dapat diartikan sebagai perangkat elektronik kecil yang memiliki fungsi khusus. Salah satu hal yang membedakan gadget dengan perangkat elektronik lainnya adalah unsur "kebaruan”. Artinya, dari hari ke hari gadget selalu muncul dengan menyajikan teknologi terbaru yang membuat hidup manusia menjadi lebih praktis. gadget sebagai teknologi yang paling diminati tentunya mempunyai dampak yang sangat positif seperti kemudahan dalam berkomunikasi, kemudahan dalam mengakses informasi dan lainnya. dari sekian banyak manfaat dari penggunaan gadget, jika tidak bijak dalam penggunakannya, gadget bisa memberi kerugian terutama untuk anak yang masih dalam usia sekolah seperti terganggunya perkembangan fisik dan psikologis dan perubahan perilaku anak.

Berdasarkanhasil penelitian (Hasella,2013:2), respondenmenggunakan gadget lebih dari 11 jam perhari dan gadget digunakan untuk browsing bahkan paling banyak digunakan untuk bermain game online dan untuk mengakses berbagai media sosial yang ada ( Instagram, Path, Facebook, twitter), mereka cenderung memiliki gadget untuk mengikuti trend yang ada saat ini. Penggunaan gadget dikarenakan tuntutan trend saat ini yang menuntut mereka untuk aktif dalam dunia internet atau media sosial, oleh karena itu pada saat jampelajaran,merekajugasering menggunakangadgetuntuk menutup irasa bosan karena jam pelajaran yang panjang. Hal ini menyebabkan bahwa sebagaian materi yang dijelaskan oleh guru tidak lagi diserap dengan baik karena peserta didik tidak mampu berkonsentrasi lagi dengan pelajaran yang sedang berlangsung, yang dapat berakibat pada nilai akademik peserta didik,juga siswa menjadi jarang berkomunikasi dengan temannya karena lebih asik dengan gadget miliknya. Disinilah letak pentingnya menanamkan sikap pengelolaan diri (Self Regulated) agar peserta didik bijak dalam menggunakan gadget, sehingga gadget bukan hanya untuk sekadar menampilkan eksistensi diri, gengsi, atau ikut ikutan modesaja tapi bisa menjadi alat penunjang dalam proses belajar.

Banyak orang beranggapan bahwa gadget dapat diibaratkan sebagai sebilah pisau. Jika mahir menggunakannya secara tepat, pisau itu dapat membantu pekerjaan 
secara tepat dan cepat. Sekali tebas maka putuslah ranting kayu. Namun, pisau itu dapat melukai pemiliknya jika tak mahir menggunakannya. Pisau itu justru akan meninggalkan jejak buruk yang berbentuk luka tak terhilangkan. Maka, alangkah baiknya jika pisau itu benar-benar digunakan untuk sesuatu yang memberikan banyak manfaat bagi pemiliknya. begitu juga dengan gadget sebagai alat yang canggih mestinya dapat memberikan banyak manfaat, akibat buruk yang muncul karena kesalahan pemakaiannya. Oleh karena itu, diperlukan kreativitas bagi pemilik gadget sehingga dampak buruk dapat dihindari dan hasil positif dapat diraih. beliau pernah melakukan Penelitian Tindakan Kelas (PTK) dengan judul Pemanfaatan "Blog untuk Meningkatkan Kompetensi Menulis Berita”, “Meningkatkan Kompetensi Bertelepon dengan Memanfaatkan Telepon Selular" dan "Pemanfaatan Gadget untuk Meningkatkan Kompetensi Menulis Pesan Singkat”. (Wahyudi, 2015 : website) Direktur EDU training center. Kutipan di atas mengingatkan bahwa guru dan orangtua mempunyai peran yang besar agar gadget dapat menjadi sumber dan alat belajar bagi peserta didik, apabila hal itu terus dilakukan, maka peserta didik akan terbiasa dan memiliki Self regulated learning yang kuat dalam mengembangkan dan meningkatkan kompetensi serta pengetahuannya.

Selfregulated learningmenekankan pentingnya tanggung jawab personal dan mengontrol pengetahuan dan keterampilan-keterampilan yang diperoleh (Zimmerman, 1990: 3 -17). Disini peserta didik diharapkan terampil serta bertanggung jawab dalam menggunakan gadget yang mereka miliki, agar dapat dimanfaatkan sebagai sumber untuk mencari dan menggali informasi sebanyak-banyaknya. Proses pembelajaran salah satunya bertujuan untuk membebaskan siswa dari kebutuhan mereka terhadap guru,sehingga para siswa dapat terus belajar secara mandiri sepanjang hidupnya dan untuk terus belajar secara mandiri makasiswa harus menjadi seorang pembelajar berdasar regulasi diri (selfregulatedlearner) (Wollfolk,2008:45).

Selfregulated learning menjelaskan betapa pentingnya otonomi dan tanggung jawab pribadi dalam kegiatan belajar. Dalam proses pembelajaran, siswa yang memiliki self regulated learning membangun tujuan belajar, mencoba memonitor, meregulasi, dan mengontrol kognisi, motivasi, dan perilakunya untuk mengontrol tujuan yang telah dibuat (Valle, 2008: 724-731). Siswa yang belajar dengan regulasi diri bukan hanya tahu tentang apayang dibutuhkan oleh setiap tugas, tetapi mereka juga dapat 
menerapkan strategi yang dibutuhkan. Mereka dapat menggunakan berbagai strategi atau mengorganisasikan materinya. Guru sebagai fasilitator dapat membantu siswa dalam memanfaatkan gadget untuk membantu jalannya proses pembelajaran.

Self Regulated Process dalam melaksanakan kegiatan belajar menurut (Smith, 2001:665).

1. Memilih untuk berprestasi

a. Efikasi Diri (self efficacy)

Konsep self efficacy mengacu pada keyakinan (belief) seseorang pada kemampuannya untuk berhasil dalam suatu bidang perilaku tertentu (Betz, 2004:340).

b. Tujuan (goals)

c. Nilai (value)

d. Atribusi (attribution)

e. Memilih Metode

Berdasarkan pembahasan di atas dapat dikatakan bahwa prestasi belajar dan kesuksesan untuk mencapai sesuatu tergantung adanya Self Regulated Learning (SRL). Penelitian dari para ahli psikologi, mengatakan bahwa yang mempengaruhi tumbuhnya Self Regulated Learning (SRL) adalah self efficacy dan dukungan social. Menurut Bandura (1997) efikasi diri adalah keyakinan seorang individu mengenai kemampuannya dalam mengorganisasi dan menyelesaikan suatu tugas yang diperlukan untuk mencapai hasil tertentu. factor pertama adalah efikasi diri yakni keyakinan bahwa seseorang bisa menguasai situasi dan mendapatkan hasil positif. Faktor kedua adalah Dukungan sosial termasuk sebagai faktor lingkungan. Baron dan Byrne (2005;75) menyatakan bahwa dukungan sosial adalah kenyamanan secara fisik \& psikologis yang diberikan oleh teman/anggota keluarga. Dukungan sosial juga dapat dilihat dari banyaknya kontak sosial yang terjadi atau yang dilakukan individu dalam menjalin hubungan dengan sumber-sumber yang ada di lingkungan. Menurut Johnson \& Johnson (1991:472) dukungan sosial berasal dari orang-orang penting yang dekat (significant others) bagi individu yang membutuhkan bantuan misalnya di sekolah seperti guru dan teman-temannya.

Dukungan sosial menjadi hal yang diduga dapat mempengaruhi self regulated learning. Orang yang mendapatkan dukungan sosial keluarga yang tinggi maka akan 
banyak mendapatkan dukungan emosional, penghargaan, instrumental, dan informatif dari keluarga. Hal tersebut berdampak pada self regulated learning individu tersebut menjadi tinggi karena individu mampu mengelola secara efektif pengalaman belajarnya sendiri di dalam berbagai cara sehingga mencapai hasil belajar yang optimal.

Siswa yang termasuk dalam kategori self-regulated adalah siswa yang aktif dalam proses belajar, baik secara metakognitif, motivasi, maupun perilaku. Mereka menghasilkan gagasan, perasaan, dan tindakan untuk mencapai tujuan belajarnya. Secara metakognitif mereka bisa memiliki strategi tertentu yang efektif dalam memproses informasi. Sedangkan motivasi berbicara tentang semangat belajar yang muncul dari dalam diri mereka sendiri (internal). Sedangkan perilaku, ditunjukkan dalam bentuk tindakan nyata dalam belajar.

Teori dari para pakar di atas menjelaskan bahwa betapa pentingnya Self Regulated terhadap penggunaan gadget oleh peserta didik. Mereka akan tumbuh menjadi generasi yang lebih kreatif dan interaktif, karena dengan bantuan gadget mereka akan lebih mudah mendapatkan beragam informasi yang juga bisa mendorong anak menjadi lebih kreatif. Oleh sebab itu, pemanfaatan gadget dalam proses pembelajaran akan menjadi strategi yang baru agar pembelajaran semakin menarik, karena mereka sudah bisa mengontrol penggunaan gadget sesuai dengan fungsi aslinya.

\section{SIMPULAN}

Dari uraian di atas tentang Self Regulated Learning (SRL) dapat ditarik kesimpulan sebagai berikut:

1. Self regulated learning dapat digunakan sebagai sebagai dorongan dan kegiatan individu untuk mengelola pembelajarannya sendiri. Disisi lain self regulated learningdapat digunakan oleh sebagian guru/dosen sebagai model/strategi pembelajaran untuk meningkatkan proses pembelajaran di kelas.

2. Penggunaan gadget akan lebih bermanfaat apabila siswa memiliki self regulated learning yang kokoh agar terhindar daripengaruh-pengaruh negatif yang akan muncul apabila tidak dikelola dengan baik.

3. Penggunaan model pembelajaran yang berbasis gadget dapat digunakan sebagai sebuah strategi pembelajaran agar lebih menarik perhatian dari peserta didik. 


\section{DAFTAR PUSTAKA}

Bandura,A.(1997).SelfEfficacy:TheExercise of Control.New York: Freeman

Baron, R. \& Byrne, D. (2005). Psikologi Sosial edisi 10. Jakarta: Erlangga

Betz. 2004. Self Regulated Learning in High-Achiever Student, (online). (www. blogsome.com./2007/10/18/artikel-artikel-self regulated learning-styles/-20), diakses tanggal 28 Oktober 2011.

Hasella, M.O.(2013). Dampak penggunaan smarthphone di kalangan pelajar.UniversitasLambung Mangkuratprogramstudiilmukomputer fakultas MIPA. http://www.slideshare.net/nur_ Anita92/metpen- 28928073. Diakses 14 November2014.

Johnson, D., Johnson, R., and Smith, K. (1991), Cooperative Learning: Increasing College Faculty Instructional Productivity, ASHE-ERIC Higher Education Report No. 4, Washington, DC: The George Washington University.

Pintrich, Paul et al. (1990). Motivational and self-regulated learning components of classroom academic performance, Journal of Educational Psychology.

Usman, Uzer. 2005. Menjadi Guru Profesional. Bandung: PT Remaja Rosdakarya.

Valle, A.,Núñez, J.C., Carlos, J., Cabanach, R.G., González-Pienda, J.E., Rodríguez, S.,Rosario,P.,Cerezo, R.,\&Muñoz- Cadavid, M.A.(2008). Self-regulated profilesandacademic achievement. Psicothema,20(4), 724-731

Wollfolk. (2008). Educational Psychology. ActiveLearningEditionTenthEdition. Boston: Allyn \&Bacon.

Wahyudi, Johan (2015). Pemanfaatan Gadget untuk Meningkatkan MutuPembelajaran.http://www.kompasiana.com/johanmenulisbuku/pemanfaata n-gadget-untuk-meningkatkan-mutupembelajaran_55176aea813311cb669de670

Zimmerman,B.J.(1986).BecomingASelf Regulated Learner. Which are the key subprocesses?ContemporaryEducationalPsychology,11, 307-313.

Zimmerman, B.J.(1990).Self Regulated Learning And Academic Achievement: An Overview. EducationalPsychologist,25(1),3-17.

Zimmerman, B. J \& Bandura, A. (1994). Impact of self-regulation influence on writing course attainment. American Educational Research Journal. 